L. Discovery and development of the complement inhibitor eculizumab for the treatment of paroxysmal nocturnal hemoglobinuria. Nat Biotechnol. 2007;25(11):1256-1264.

5. Schmidtko J, Peine S, El-Housseini Y, Pascual M, Meier P. Treatment of atypical hemolytic uremic syndrome and thrombotic microangiopathies: a focus on eculizumab. Am J Kidney Dis. 2013 61(2):289-299.

6. Gehrs KM, Anderson DH, Johnson LV, Hageman GS. Age-related macular degeneration - emerging pathogenetic and therapeutic concepts. Ann Med 2006;38(7):450-471.

7. Ricklin D, Hajishengallis G, Yang K, Lambris JD. Complement: a key system for immune surveillance and homeostasis. Nat Immunol. 2010; 11(9):785-797.

8. Tortajada A, et al. C3 glomerulopathy-associated CFHR1 mutation alters FHR oligomerization and complement regulation. J Clin Invest. 2013;123(6):2434-2446.

9. de Cordoba SR, Tortajada A, Harris CL, Morgan BP. Complement dysregulation and disease: from genes and proteins to diagnostics and drugs. Immunobiology. 2012;217(11):1034-1046.

10. Józsi M, Zipfel PF. Factor H family proteins and human diseases. Trends Immunol. 2008;29(8):380-387.

11. Hughes AE, Orr N, Esfandiary H, Diaz-Torres M, Goodship T, Chakravarthy U. A common CFH haplotype,with deletion of CFHR1 and CFHR3,is associated with lower risk of age-related macular degeneration. Nat Genet. 2006;38(10):1173-1177.

12. Skerka C, Zipfel PF. Complement factor $\mathrm{H}$ related proteins in immune diseases. Vaccine. 2008;26(suppl 8):I9-I14.

13. Fakhouri F, Frémeaux-Bacchi V, Noël LH, Cook HT, Pickering MC. C3 glomerulopathy: a new classification. Nat Rev Nephrol. 2010;6(8):494-499.

14. Malik TH, et al. A hybrid CFHR3-1 gene causes familial C3 glomerulopathy. J Am Soc Nephrol. 2012;23(7):1155-1160.

15. Gale DP, et al. Identification of a mutation in complement factor H-related protein 5 in patients of Cypriot origin with glomerulonephritis. Lancet. 2010;376(9743):794-801

16. Pangburn MK, Rawal N, Cortes C, Alam MN, Ferreira VP, Atkinson MA. Polyanion-induced self-association of complement factor H. J Immunol. 2009;182(2):1061-1068.

17. Perkins SJ, Nan R, Li K, Khan S, Miller A. Complement Factor H-ligand interactions: Self-association, multivalency and dissociation constants. Immunobiology. 2012;217(2):281-297.

18. Goicoechea de Jorge E, et al. Dimerization of complement factor $\mathrm{H}$-related proteins modulates complement activation in vivo. Proc Natl Acad Sci US A. 2013;110(12):4685-4690.

19. Heinen S, et al. Factor H-related protein 1 (CFHR-1) inhibits complement C5 convertase activity and terminal complex formation. Blood. 2009;
114(12):2439-2447

20. Fritsche LG, et al. An imbalance of human complement regulatory proteins CFHR1, CFHR3 and factor $\mathrm{H}$ influences risk for age-related macular degeneration. Hum Mol Genet. 2010;19(23):4694-4704

21. Morgan HP, et al. Structural basis for engagement by complement factor $\mathrm{H}$ of $\mathrm{C} 3 \mathrm{~b}$ on a self surface. Nat Struct Mol Biol. 2011;18(4):463-470.

22. Siegel C, et al. Complement factor H-related proteins CFHR2 and CFHR5 represent novel ligands for the infecction-associated CRASP proteins of Borrelia burgdorferi. PLoS One. 2010;5(10):e13519.

23. Hebecker M, Józsi M. Factor H-related protein 4 activates complement by serving as a platform for the assembly of alternative pathway $\mathrm{C} 3$ convertase via its interaction with $\mathrm{C} 3 \mathrm{~b}$ protein. J Biol Chem. 2012;287(23):19528-19536.

24. Banda NK, et al. Essential role of surface-bound complement factor $\mathrm{H}$ in controlling immune complex-induced arthritis. J Immunol. 2013; 190(7):3560-3569.

25. Vik DP, Muñoz-Cánoves P, Kozono H, Martin LG, Tack BF, Chaplin DD. Identification and sequence analysis of four complement factor $\mathrm{H}$-related transcripts in mouse liver. J Biol Chem. 1990;265(6):3193-3201

26. Hellwage J, et al. Two factor H-related proteins from the mouse: expression analysis and functional characterization. Immunogenetics. 2006; 58(11):883-893.

\title{
Transplant rejection and paradigms lost
}

\author{
Terry B. Strom
}

Beth Israel Deaconess Medical Center, Harvard Medical School, Boston, Massachusetts, USA.

\begin{abstract}
During transplant rejection, migrating $T$ cells infiltrate the grafted organ, but the signals that direct this migration are incompletely understood. In this issue of the JCI, Walch et al. debunk two classical paradigms concerning transplant rejection, with important consequences for the design of antirejection therapeutics.
\end{abstract}

Transplant rejection begins with the migration and influx of recipient $T$ cells into the transplant. Many, but not all, of these $\mathrm{T}$ cells bear TCRs specific for donor alloantigen. If migration to and infiltration of the transplant by tissue-damaging anti-donor $\mathrm{T}$ cells can be neutralized, even temporarily, the recipient anti-donor allograft response would be significantly weakened and more amenable to low-dose or tolerizing therapies.

The current dogma explaining the initial phases of the allograft response is based on the leukocyte migration paradigm (1). Chemokines, a family of small transmembrane proteins that attract migratory $\mathrm{T}$ cells bearing specific receptors for them,

Conflict of interest: The author has declared that no conflict of interest exists.

Citation for this article: J Clin Invest. 2013; 123(6):2360-2362. doi:10.1172/JCI69385. are believed to draw $\mathrm{T}$ cells to the transplant. Then, the interaction of $\mathrm{T}$ cell surface integrins with molecules present on donor endothelial cells retain $\mathrm{T}$ cells and enable their transmigration into the transplant. When chemokines interact with chemokine receptors, chemokine receptor-associated $\mathrm{G} \alpha_{i}$ proteins are activated, and a pertussis toxin-sensitive signaling cascade is initiated. The downstream $G \alpha_{i}$ signaling pathway induces conformational changes in the integrins expressed on chemokine-activated T cells (2). These changes enhance the affinity of integrins such as VLA-4 for surrounding tissues, thought to be endothelial venules, of the transplant (Figure 1).

Chemokine production is markedly amplified within inflamed tissues, and transplant procedures, especially those involving deceased donors, inevitably lead to ischemia-reperfusion injury, resulting in inflam- mation of the endothelium and chemokine expression $(3,4)$. Thus, it has been widely believed that chemokines, which regulate $\mathrm{T}$ cell traffic in lymphoid tissue, also play a pivotal role in transplant rejection.

Against this theoretical backdrop, and influenced by the surprisingly weak therapeutic effect of antibodies directed against chemokine receptors upon transplant survival (5-7), Walch et al. tested the authenticity of the classical leukocyte migration paradigm in mouse cardiac and renal transplant models (8). In short, they confirmed an important role for the integrin VLA-4, but found that the paradigm did not hold true for the role of chemokines in directing the massive influx of recipient anti-donor $T$ cells in the allograft response.

\section{Chemokine receptor signaling in the allograft response}

To investigate the role of chemokine receptors in the allograft response, Walch et al. used passive $\mathrm{T}$ cell transfer models in which recipient strain $T$ cells are injected into syngeneic lymphopenic hosts. They found that infiltration into allografts by pertussis toxin-treated memory or acti- 
A

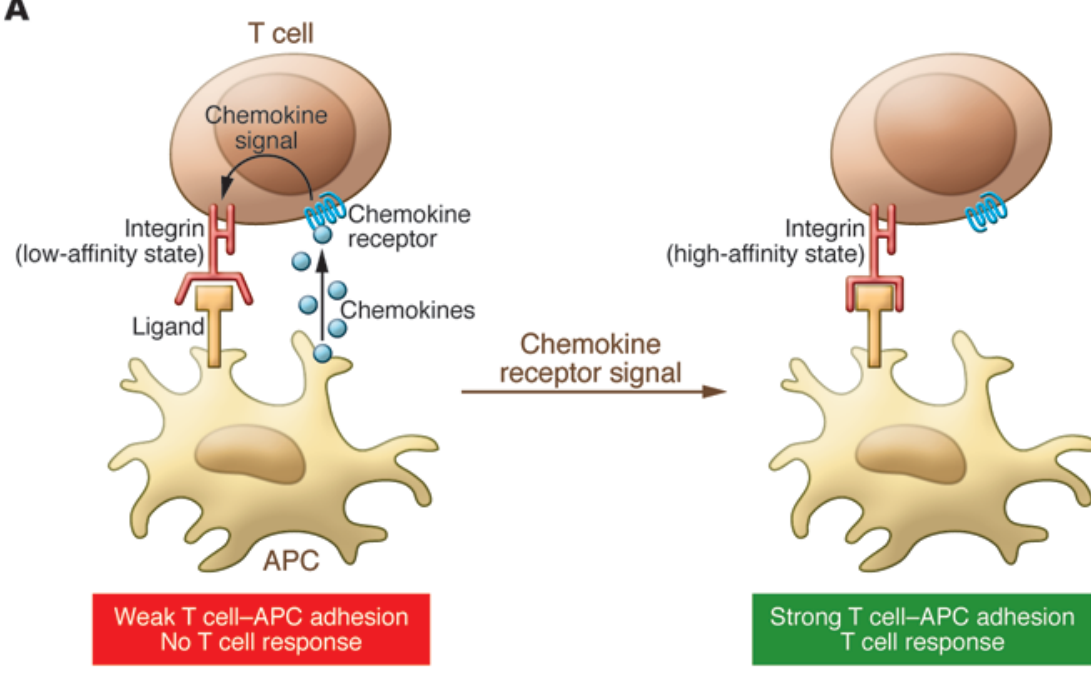

B
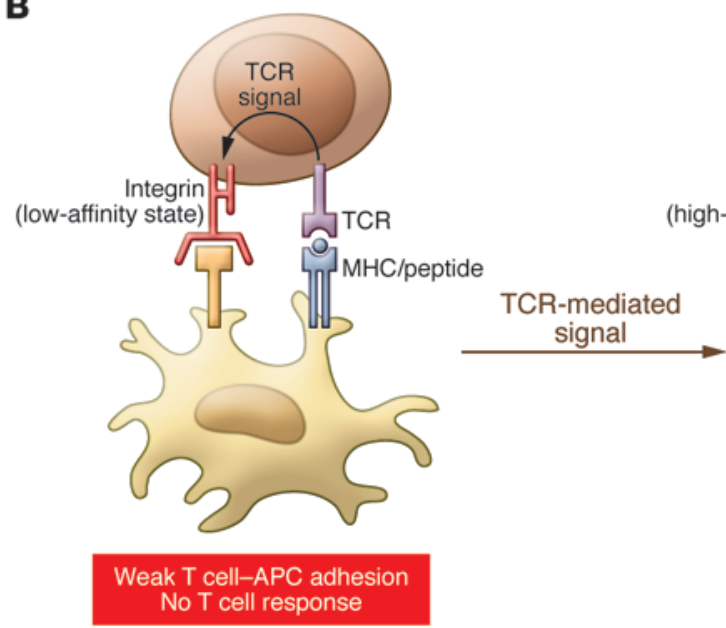

\section{(n)}
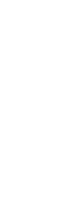

\section{Figure 1}

Integrin avidity determines T cell infiltration of transplants. (A) Low-affinity integrins in resting T cells are converted to a high-affinity state by exposure to chemokines, also a stimulus for migration of non-donor-reactive T cells to the transplant. (B) Integrin affinity may also be altered by antigen recognition, which initiates infiltration of the transplant by T cells bearing TCRs for transplant antigens. Figure adapted with permission from Cellular and Molecular Immunology (14).

vated effector $\mathrm{CD}^{+} \mathrm{T}$ cells previously stimulated with donor cells was unimpaired, whereas migration to lymph nodes was affected (8). Hence, migration of memory or activated effector $\mathrm{CD}^{+}$ $\mathrm{T}$ cells to the allograft is not dependent upon activation of chemokine receptors. The same conclusions were reached in experiments analyzing rejection of newly engrafted organs, when inflammation caused by ischemia-reperfusion injury is present, and in hosts in which transfer of lymphocytes was delayed to 50 days after transplantation, after dissipation of ischemia-reperfusion-related inflammation. In these experiments, rejection mediated by pertussis toxin-treated donor-reactive memory $\mathrm{T}$ cells was only slightly delayed compared with controls (8).

That chemokine-stimulated migration of donor-reactive $\mathrm{CD}^{+}$activated effector or memory $\mathrm{T}$ cells to host lymphoid tissue is not a necessary prelude to infiltration and rejection of the transplant was corroborated by experiments in transplant recipients that lack secondary lymphoid tissues (e.g., lymph node and spleen). Interestingly, purified and passively transferred naive $T$ cells or even memory-type $T$ cells that do not recognize donor antigens did not infiltrate the transplant unless these nondonor-reactive $T$ cells were cotransferred with donor-reactive T cells. Thus, in stark contrast to the previously accepted dogma, infiltration of donor-reactive $\mathrm{CD}^{+} \mathrm{T}$ cells into the transplant and rejection are not dependent upon chemokines.

\section{TCR activation and donor-reactive $T$ cell migration to the transplant}

If chemokines emanating from an inflamed endothelium are not involved in drawing donor-reactive $T$ cells into the transplant, what is responsible for this crucially important step in the allograft response? Walch et al. confirmed an important role for integrins in enabling infiltration of the allograft, but their results made clear the chemokine receptor $G \alpha_{i}$ signaling pathway is not involved. Knowing that activation of the TCR complex, like activation of chemokine receptors, induces functionally critical conformational change in integrins, the authors studied the role of donor antigen in the influx of $\mathrm{CD}^{+}$ donor-reactive and non-donor-reactive T cells. Again, a passive lymphocyte transfer system was used, but in this series of experiments, $\mathrm{CD}^{+} \mathrm{T}$ cells were harvested from mice bearing transgenic TCRs that do or do not recognize donor antigen. Both sets of $\mathrm{T}$ cells were able to infiltrate transplants; however, $T$ cells that do not express receptors for donor antigen did not infiltrate transplants unless accompanied by TCR donor-reactive T cells. These $\mathrm{T}$ cell populations also differed in their requirements for chemokine receptor or TCR activation in infiltrating the transplant (Figure 1). Inactivation of the chemokine receptor-linked $\mathrm{G \alpha}_{i}$ protein signaling pathway with pertussis toxin prevented migration of $\mathrm{CD} 8^{+} \mathrm{T}$ cells bearing the non-donor-reactive TCR complex, but not $\mathrm{T}$ cells bearing the donor-reactive TCR complex (8). Similar conclusions have emerged in an analysis of $\mathrm{T}$ cell migration in an autoimmune mouse model of type 1 diabetes $(9,10)$.

Walch et al. performed two-photon intravital imaging to further analyze infiltration by TCR transgenic CD8 ${ }^{+} \mathrm{T}$ cells. Donor antigen-initiated responses, but not chemokine receptor-initiated responses, were shown to be responsible for the migration and adhesion of $\mathrm{CD}^{+}$donor-reactive TCR T cells to the capillary lumina, which in turn led to transmigration of donorreactive effector $T$ cells into the transplant. Previously, donor endothelial cells were believed to be solely responsible for presentation of antigen to $\mathrm{T}$ cells migrating into 
the vascular lumen (11). However, Walch et al. found that bone marrow-derived APCs such as dendritic cells were more effective in retaining $\mathrm{T}$ cells within the graft than were endothelial cells. Infiltration of nondonor-reactive $T$ cells into the transplant was enabled by cotransfer with donor-reactive T cells (8).

\section{Clinical implications}

Even perfect matching of major histocompatibility locus antigens between donor and recipient does not obviate the need for immunosuppressive therapy, because mismatches for the myriad of minor histocompatibility antigens can also lead to rejection. As blockade of chemokine/ chemokine receptor interactions will not block the initial stages of rejection, an alternative approach might be to treat with antibodies directed at the TCR complex.

Indeed, treatment with antibodies directed at a nonpolymorphic component of the TCR complex provides a wellappreciated therapeutic option to block the initial stages of the allograft response. Upon TCR activation, CD3 proteins polymerize with $\mathrm{T}$ cell antigen receptor protein (reviewed in ref. 12). Stimulation of the TCR complex by anti-CD3 leads to polymerization with the TCR, transiently activating $\mathrm{T}$ cells. Subsequently, $\mathrm{T}$ cell activation leads to an outpouring of proinflammatory cytokines, before the TCR complex is lost from the cell surface and immunosuppressive and even immune tolerance-promoting effects are obtained. Attempts to obviate these side effects by structural changes in the antibody have proven partially, but not totally, successful $(12,13)$. Further improvements in antibody design or adaptation of multiagent strategies that enable successful treatment with lower and safer doses of anti-CD3 are required. The work of Walch et al. (8) serves to refocus attention on the initiation of the allograft response from the chemokine/chemokine receptor pathway toward activation of the TCR complex. While paradigms may be dashed, this work elucidates the molecular basis of the initial stages of the allograft response. This newly obtained and more complete understanding of this process will have substantial implications for transplant medicine.

\section{Acknowledgments}

T.B. Strom is funded by grants awarded by the NIH (NIAID and NIDDK) and the Juvenile Diabetes Research Foundation.

Address correspondence to: Terry B. Strom, Beth Israel Deaconess Medical Center, 330 Brookline Avenue, E/CLS 608, Harvard Medical School, Boston, Massachusetts 02215, USA. Phone: 617.735.2880; Fax: 617.667.0923; E-mail: tstrom@bidmc. harvard.edu.

1. Springer TA. Traffic signals for lymphocyte recirculation and leukocyte emigration: the multistep paradigm. Cell. 1994;76(2):301-314.

2 . Bolt $\mathrm{S}$, et al. The generation of a humanized, non-mitogenic CD3 monoclonal antibody which retains in vitro immunosuppressive properties. Eur J Immunol. 1993;23(2):403-411.

3. Shulman $Z$, et al. Lymphocyte crawling and transendothelial migration require chemokine triggering of high-affinity LFA-1 integrin. Immunity. 2009; 30(3):384-396

4. Famulski KS, et al. Molecular phenotypes of acute kidney injury in kidney transplants. J Am Soc Nephrol. 2012;23(5):948-958.

5. Hancock WW, Gao W, Faia KL, Csizmadia V. Chemokines and their receptors in allograft rejection. Curr Opin Immunol. 2000;12(5):511-516.

6. Halloran PF, Fairchild RL. The puzzling role of CXCR3 and its ligands in organ allograft rejection. Am J Transplant. 2008;8(8):1578-1579.

7. Oberbarnscheidt $\mathrm{MH}$, et al. Memory T cells migrate to and reject vascularized cardiac allografts independent of the chemokine receptor CXCR3. Transplantation. 2011;91(8):827-832

8. Walch JM, et al. Cognate antigen directs $\mathrm{CD}^{+} \mathrm{T}$ cell migration to vascularized transplants. J Clin Invest. 2013;123(6):2663-2671.

9. Calderon B, Carrero JA, Miller MJ, Unanue ER. Cellular and molecular events in the localization of diabetogenic T cells to islets of Langerhans. Proc Natl Acad Sci U S A. 2011;108(4):1561-1566.

10. Calderon B, Carrero JA, Miller MJ, Unanue ER. Entry of diabetogenic $\mathrm{T}$ cells into islets induces changes that lead to amplification of the cellular response. Proc Natl Acad Sci U S A. 2011;108(4):1567-1572.

11. Pober JS, Tellides G. Participation of blood vessel cells in human adaptive immune responses. Trends Immunol. 2012;33(1):49-57.

12. Chatenoud L, Bluestone JA. CD3-specific antibodies: a portal to the treatment of autoimmunity. Nat Rev Immunol. 2007;7(8):622-632.

13. Keymeulen B, et al. Insulin needs after CD3-antibody therapy in new-onset type 1 diabetes. $N$ Engl J Med. 2005;352(25):2598-2608.

14. Abbas AK, Lichtman AH, Pober JS. Cellular and Molecular Immunology. 4th ed. Philadelphia, Pennsylvania, USA: Saunders; 2000.

\title{
Blazing a new TRAIL in hematopoietic cell transplantation
}

\author{
Nelson Chao \\ Duke University Medical Center, Bone Marrow Transplant Program, Durham, North Carolina, USA.
}

\begin{abstract}
There is a ying/yang to most biological therapies, and the balance of efficacy versus toxicity is delicate and sometimes difficult to achieve in favor of the patients. When the therapeutic window is wide, these therapies can be used in the majority of patients, but when the therapeutic window is narrow, the decision to proceed must be carefully balanced with a thoughtful risk-benefit analysis. In this issue of the JCI, Ghosh et al. tackle one of the major obstacles in hematopoietic cell transplantation (HCT) technology: balancing the beneficial antitumor effect with the harmful anti-host effect.
\end{abstract}

Conflict of interest: The author has declared that no conflict of interest exists.

Citation for this article: J Clin Invest. 2013; 123(6):2362-2363. doi:10.1172/JCI69909.
HCT describes the process of introducing new donor cells into a host, most often to treat hematological malignancy. The aim of treatment is to replace the dam- aged hematopoietic cells with normal stem cells, and requires the rebuilding of a new immune system, since the original needs to be destroyed to allow for donor engraftment. The new immune system can recognize virulent microbial agents, alloantigens, and tumor-specific antigens, leading to the beneficial graft-versus-tumor/leukemia (GVL) effect. On the other hand, donor $\mathrm{T}$ cell recognition of host antigens can result in graft-versushost disease (GVHD) (1). The occurrence of GVHD is the single greatest obstacle 